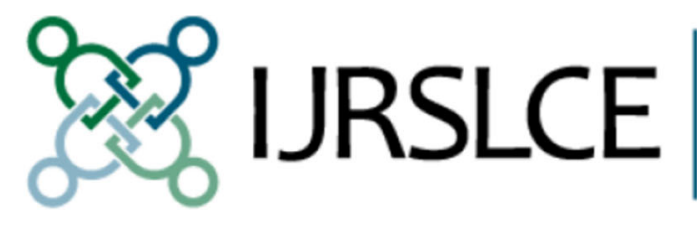

International Journal

for Research on

Service-Learning \&

Community Engagement

Volume 3 | Issue 1

Article 3

2015

Be Mindful of Your Discomfort: An

Approach to Contextualized Learning

\author{
Angie Bheekie \\ Mea van Huyssteen
}

This article was originally published at:

https://journals.sfu.ca/iarslce/index.php/journal/article/view/129/79

Recommended Citation

Bheekie, A., \& Huyssteen, M. V. (2015). Be mindful of your discomfort: An approach to contextualized learning. International Journal of Research on Service-Learning and Community Engagement, 3(1), Article 3. 


\title{
Be Mindful of Your Discomfort: An Approach to Contextualized Learning
}

\author{
Angeni Bheekie \\ Mea van Huyssteen
}

University of the Western Cape, South Africa

\begin{abstract}
Service-learning creates a space for contextualized learning whereby students connect classroom concepts to real-world practices relative to their own frame of reference. These experiences occur within a societal status quo rooted within historical and social inequalities. Affective responses to encounters with inequalities are not routinely addressed within the learning outcomes of formal curricula. Thus, the pedagogy of discomfort calls for an awareness and a critical self-examination among educators and students of how their passive acceptance or non-acceptance of apparent social injustices has been shaped by the status quo. By incorporating affective learning into the reflective process, we realized that contradictions in South African society permeate students' experiences in ways that are indicative of the status quo. Increased recognition of the potential of affective learning to address social injustices in higher education could enable efforts toward social transformation.
\end{abstract}

Keywords: affective learning, pedagogy of discomfort, reciprocity, service-learning, social justice

Washing one's hands of the conflict between the powerful and the powerless means to side with the powerful, not to be neutral.

-Paulo Freire

Service-learning experiences create a space for contextualized learning (Bringle \& Hatcher, 1999) whereby students, through reflection, are encouraged to connect theories from the classroom to real-world practices relative to their own frame of reference. What makes service-learning different from other experiential learning approaches is its focus on civic engagement, underpinned by reciprocity among students, educators, and the community (Flecky, 2011). By focusing activities on addressing community needs, service-learning purposefully challenges participants to engage with diversity and social injustice (Eyler \& Giles, 1999). Indeed, one of the most consistent outcomes of service-learning has been to inculcate tolerance for diversity among students (Skilton-Sylvester \& Erwin, 2000).

However, by inculcating tolerance of diversity (i.e., acceptance), there exists an inherent risk of adding passivity, or a "thickness," to service-learning experiences (Boyte, 2003). In this way, servicelearning may maintain the status quo rather than effect social transformation. It has been suggested that critical reflection that challenges the status quo offers people the opportunity to question commonly held practices, customs, and rituals retained through societal power relationships that have remained largely unchanged (Hafferty, 1998; Merriam, 2004). Megan Boler (1999) suggested using discomforting emotional responses as starting points to examine how the status quo has shaped peoples' ways of accepting or not accepting instances of social inequalities. 
The purpose of this article is to create an understanding of affective student learning in the context of service-learning and within the theoretical framework of the pedagogy of discomfort. We first present Boler's (1999) pedagogy of discomfort and discuss how this pedagogy may be applied in service-learning as a tool toward transformative learning and in strengthening students' critical thinking. We then integrate this framework by contextualizing it in South Africa, a society in transition. Further, we reflect on and interpret how these theoretical concepts have contributed - and are limited in their application - to higher education. Finally, we examine higher education's stance on issues of social injustice and illustrate how integrating the pedagogy of discomfort in service-learning could serve as a catalyst toward social transformation.

\section{Pedagogy of Discomfort}

Megan Boler (1999) introduced the pedagogy of discomfort in her book Feeling Power: Education and Emotions. During the Persian Gulf War, students "coped" by disengaging with media coverage, thus denying the war and not talking about it, which Boler attributed to feelings of powerlessness and numbness. She emphasized that students felt powerless to effect change and that repetitive media images of the war led to affective desensitization reinforcing numbness as a survival response. Powerlessness manifested itself as silence, leading to guilt or self-hatred, thus distancing students from human connections and adding to a sense of isolation and denial. Freire's statement in the epigram that begins this article further reflects that one's isolation from issues of social inequality only widens this gap and reinforces a power relationship between the powerful and the powerless. Boler noted that survival numbness becomes a choice: People impose emotional barriers between themselves and "others" and society, whereby they become passive observers, undertaking a "spectating" role. Boler revealed that without informed options for alternatives, numbness may be the inadvertent effect of cultural illiteracy with respect to translating emotions into knowledge and action.

As a coping response to injustices, self-imposed isolation not only occurs at an individual level, but also extends to the societal level, manifesting as identity politics, power relations, and fear (see Figure 1). These barriers are defined by a binary attitude easily reinforced through identity politics which includes matters of diversity (e.g., race, language, age, gender, culture, socioeconomic status). Boler (1999) defined the binary attitude as "us and them," in which one side of the binary is viewed as "us," "good," "right," and "moral," reflecting the status quo or the dominant culture. Drawing from these binary limitations, people establish distances between themselves which perpetuate denial and reinforce the status quo. Thus, the binary mentality may be interpreted as a survival strategy, protecting people who are coping with social injustice.

Boler (1999) further illustrated how the dominant culture reinforces emotions that it deems either acceptable or unacceptable, and how teaching institutions are biased by these mainstream ideas by (not) allowing "undesirable" (either "bad, evil or wrong") emotions into the classroom. The students' and their teachers' inability to converge toward engaging with their feelings of isolation led Boler to ask, "What kind of community do we compose in our institutional settings?"

\section{Binary Mentality, Power Relations, and Higher Education Institutions}

Binary mentalities are prevalent in higher education institutions, especially in science disciplines, which favor cognitive learning ("hard skills") as the benchmark for success and deny the affective side of learning ("soft skills"). A higher education institution's autonomy offers educators the freedom to prioritize research outputs and throughputs, which are driven by economic demands (i.e., the status quo), isolating them from engaging with issues of social injustice. Inevitably, such a stance allows institutions to use their isolation (as "ivory towers") to position themselves on the "right" side of the binary, thereby exercising a power relationship over communities and reinforcing the difference between the two. 
Boler (1999) attested that through their power relations, institutions resort to maintaining silences and proliferating discourses that deny affective learning, thereby determining what can and cannot be felt or expressed by those who work and learn within those institutions. This could mean that the classroom is akin to a sanctuary where educators and students alike isolate themselves from "outside" political and economic events. Boler noted that "educational institutions have no commitment to community beyond the necessary behavioural requirements that enables bureaucracy" (1999: 141).

Power relations in traditional teaching are inherent between the educator and student; the educator is seen as an authority figure (an expert who "knows" the answers), while the student assumes a subordinate role (a novice who "does not know"). Educators retain their authority by maintaining isolation and distance from students. By contrast, in service-learning the roles of educators and students are supposed to be blurred, with the educator serving as a facilitator.

\section{Passive Empathy}

Empathy is an important attribute in bridging divisions and developing community, and it represents the core of a service experience. Boler (1999) highlighted fear (of the powerful, of being caught on the "wrong" side of the binary) as a way to silence discourses, deny one's vulnerabilities, and camouflage feelings of powerlessness, thus impairing one's ability to empathize with others. "Passive empathy," according to Boler, occurs from within self-imposed barriers, where the focus is on the self, reflecting a sense that "what has happened to you might happen to me," perpetuating the cycle of fear and silence, and reinforcing numbness and isolation as a survival strategy. This self-induced isolation allows an observer to create an illusion of being at a safe distance, immersed in one's comfort zone and situated in an objective position of power. Evaluating the other's experience (as either serious or trivial, their fault or not) denies any connection with the other, endorsing the passive spectator role and, therefore, social injustice.

\section{Spectating and Witnessing Roles in Social Injustice}

Boler (1999) maintained that empathy is produced within networks of power relations and that these relations define interactions between the observer and the observed. A passive observer or spectator is one who displays passive empathy, without self-reflection, and demonstrates no ability to take action against injustice because he or she cannot overcome the self- and societally imposed barriers. Spectating assumes many forms through pleasurable experiences, diversions, and easy identification with dominant representations of good and evil that reinforce the binary mentality; it signifies learned and chosen modes of visual omission and leads to emotional selectivity, which permits a distance between oneself and others, allowing the observer to remain anonymous and deny the presence of social injustice (see Figure 1). Witnessing, by contrast, is a dynamic process requiring one to move across self-imposed and societal barriers, explore both sides of the binary, and embrace their contradictions. In this way, judgement is suspended as any one side of the binary is not necessarily viewed as "better" than the other. Thus, by being able to "bear witness" to ambiguities, contradictions, and internal struggles associated with social injustices, and by articulating the causes of and possible alternatives for them, one might achieve action empathy (see Figure 2). Boler's pedagogy of discomfort calls not only for inquiry, but also for actionaction that is catalysed as a result of learning to bear witness. Figures 1 and 2 illustrate the profiles of the spectating and witnessing stages, respectively. 


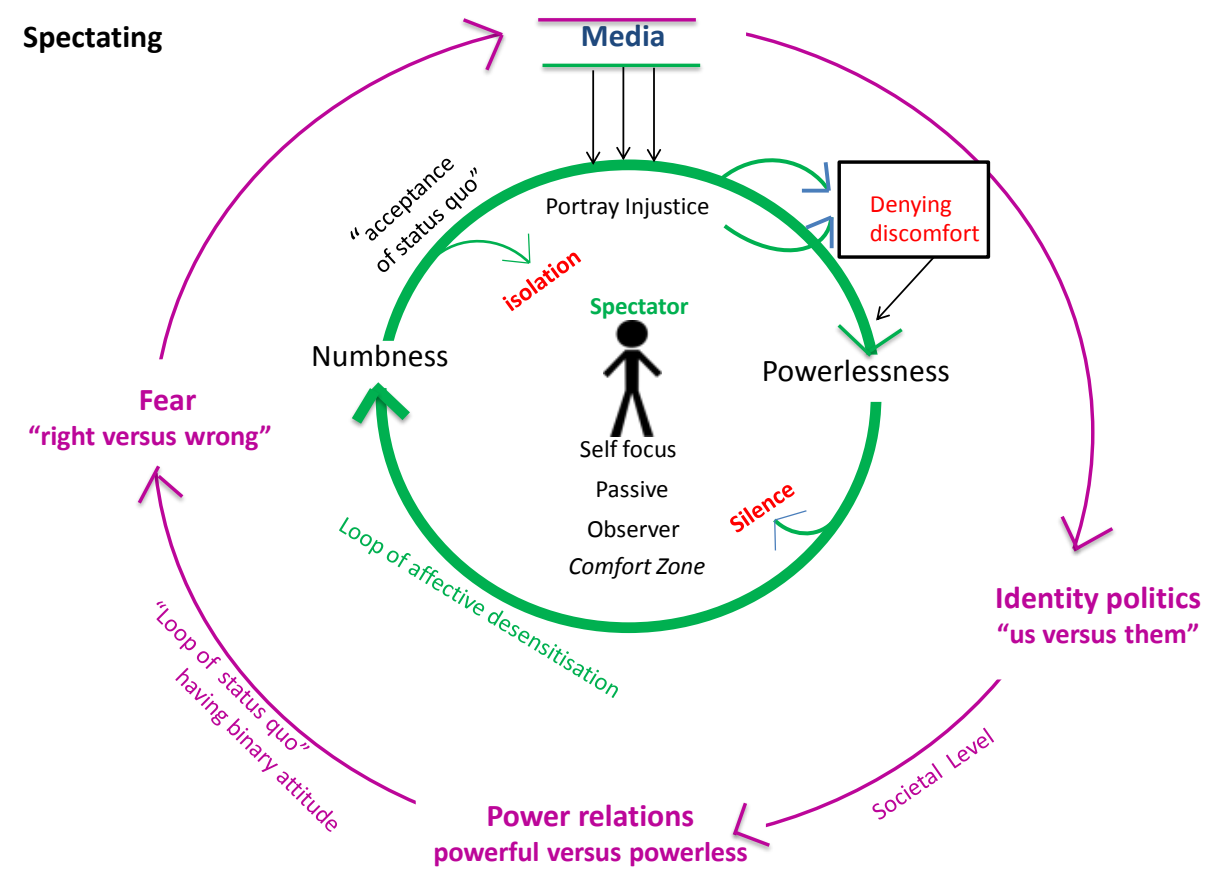

Figure 1. The spectating profile as it relates to maintaining the binary, status quo, and dominant culture by denying emotional responses (discomfort).

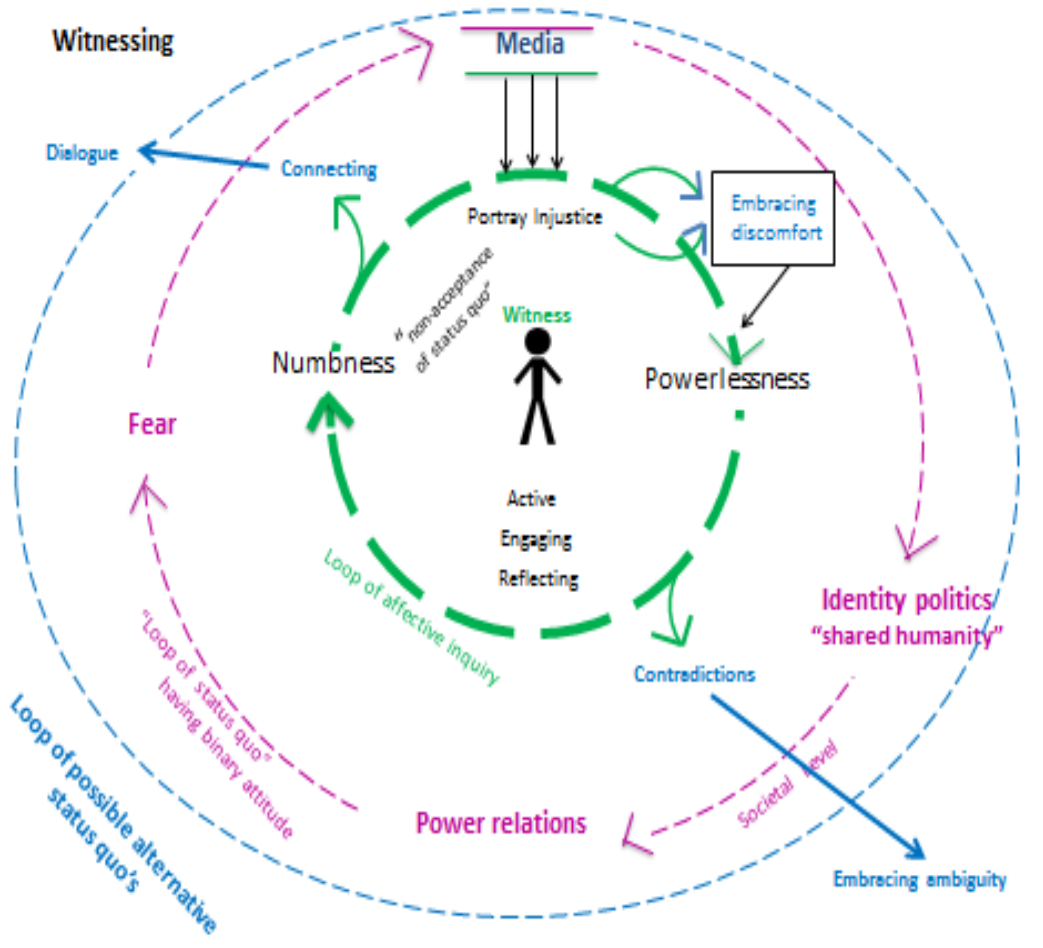

Figure 2. The witnessing profile as it relates to engaging the binary, status quo, dominant culture, and emotional responses (discomfort) to embrace ambiguity. 


\section{Learning, Teaching, and Becoming Mindful of Discomfort}

Service-learning provides students with authentic learning experiences in a real-world context. These learning experiences are informed by the students' identification and association with certain societal groups, coded through cultural, social, educational, economic, political or psychological contexts that are inextricably linked to identity politics of the pedagogy of discomfort.

Reflecting on such differences enables students to examine the triggers for habitual ways of responding to or interpreting interactions that are aligned with their own frame of reference (De Weerdt et al., 2006). According to Mezirow (1997),

a frame of reference encompasses cognitive, conative and emotional components composed of two dimensions: habits of mind and a point of view. Habits of mind are broad, abstract, orienting, habitual ways of thinking, feeling and acting influenced by assumptions that constitutes a set of codes... These habits of mind become articulated in a specific point of view - the constellation of belief, value judgement, attitude and feeling that shapes a particular interpretation (1997:5-6).

A frame of reference is constructed and reinforced through experiences, memories, and responses (Mezirow, 1998), signifies a comfort zone for people to operate from, and is synonymous with the spectator. As with service-learning, experiential learning is subjective and personally unique since learning is shaped by the way one perceives and analyses an experience, which is based on what one has been taught to see or not to see, as determined by the status quo of the dominant culture, according to Boler's (1999) pedagogy of discomfort.

Experience is a matter of the body receiving sensations which initially have no meaning but then are transformed into the language of one's brain, mind, and learning (Jarvis, 2009). Learning is also a social interaction that takes place through a combination of different processes in the body (genetic, physical, and biological) and mind (knowledge, skills, attitudes values, emotions, beliefs, and senses). An experience is therefore interpreted cognitively, emotively, or practically and integrated into a person's biography, resulting in greater self-awareness (Jarvis, 2009).

The type of learning that inculcates the ability to cross barriers - as examined by the pedagogy of discomfort and typified by in service-learning-functions at the higher orders of learning. While cognitive learning assists in understanding concepts; higher order forms of learning are aimed at redefining people's assumptions, which influence their response to the social context (Bramming, 2007). For example, in health education reform, the three levels of learning, namely informative, formative, and transformative, also illustrate the value of higher order learning this (Frenk et al., 2010; Boelen et al., 2012). At the informative level, which focuses on learning academic content, students are challenged with a plethora of discipline-focused information (theories, principles, and concepts) and skills aimed at competency development. This level correlates with binary thinking. At the formative level, professional attributes are inculcated, and learning objectives focus on the student's ability to socialize in ways guided by ethical and value-based behaviours - that is, "acceptable" ways of interacting in society, or the status quo, as described by the pedagogy of discomfort. At this level, students are also expected to be able to translate learned theory into the "real world" workplace or practice setting. By exposing gaps, as they relate (or don't relate) to discipline-based theoretical content and practice patterns, contradictions emerge that cannot be solved at the level of the binary. At the transformative level, the objective is to develop leadership attributes whereby students are able to engage with the binary, dialogue about the status quo, and negotiate toward common ground by focusing on similarities - all in order to prepare them as agents of change (Boelen, Dharmasi, \& Gibbs, 2012). Similarly, in service-learning, the tenet of reciprocity underlines engagement with communities and service partners to develop transparent, cooperative relationships built on mutual understanding that enables them to achieve a common vision of social justice. 
Transformative learning is defined as learning that develops frames of reference in order for an individual to become more inclusive, open, and emotionally able to change, and that involves awareness of situations and willingness to develop new or revised courses of action (Mezirow, 1997). Kegan (1980) used a constructive-developmental approach to differentiate between informative and transformative learning. He posited that informative learning brings changes in what we know about or add to an existing frame of reference, whereas transformative learning changes how we know or reconstruct the frame of reference (Kegan, 2009). One explanation of this difference centers on the movement from a "subject" to an "object" state of self-discovery. The subject state entails those elements of knowing or organizing that one identifies with or is embedded in - thus correlating with the concept of the spectator in the pedagogy of discomfort. The object state releases an individual from those elements of one's knowing or organizing but enables the person to examine, reflect on, and respond to elements that allow one to bear witness. A shift from the subject-object relationship is progressive in that it represents individuals' increased ability to make sense of their experiences. As meaning-making evolves, thinking becomes less rigid, simple, and elusive and more flexible, open, complex, and accommodating of contradictions. Similar to learning, teaching in health education is influenced at three levels (see Table 1).

Table 1. Levels of Teaching, Learning, and source of the Learning Tension

\begin{tabular}{l|l|l}
\hline \multicolumn{1}{c|}{ Teaching } & \multicolumn{1}{c}{ Learning level } & \multicolumn{1}{c}{ Learning tension stimulus } \\
\hline Formal curriculum & Informative & Cognitive \\
\hline Informal curriculum & Formative & Social / behavioural \\
\hline Hidden curriculum & Transformative & Emotional/ Affective \\
\hline
\end{tabular}

The first level represents the overt formal scripted curriculum, primarily binary in its approach, focusing on development of cognitive abilities and aiming for a "pass or fail" outcome, which faculty explicitly endorse. The second level is the informal curriculum, through which the unscripted and interpersonal form of teaching and learning occurs between educators and students, and which is bound within a binary context. The third level is the hidden curriculum, which functions at the level of the status quo (Hafferty, 1998). In contrast with the largely theoretical and formal fixed binary curriculum, the informal and hidden curricula are increasingly representative of the societal status quo or dominant culture - that is, the environment that underpins the learning in service-learning.

By denying the value of learning from the informal and hidden curricula-which focus on behavioural and affective abilities - educational institutions and educators endorse the societal status quo and its resultant social inequalities. By identifying and confronting the binary and engaging with it, however, service-learning encourages one to recognize and articulate the complexity of the real-world environment. Table 2 outlines examples of the binary approach in the curriculum, learning levels, and learning tension stimuli, comparing traditional teaching and service-learning and illustrating the overlap between service-learning and the pedagogy of discomfort. 
Table 2. Summary Characteristics between the Spectator and Witness Profile of the Pedagogy of Discomfort and Service-Learning as it Relates to Teaching and Learning

\section{Pedagogy of Discomfort}

\begin{tabular}{|c|c|c|c|}
\hline & \multicolumn{2}{|l|}{ 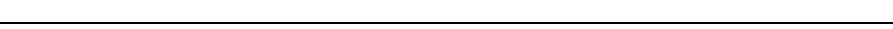 } & \multirow[b]{2}{*}{ Service-learning } \\
\hline & Spectator & Witness & \\
\hline \multicolumn{4}{|c|}{ Teaching level (educators) } \\
\hline Formal & $\begin{array}{l}\text { Neutral classroom teaching. } \\
\text { Based on and subjected to } \\
\text { binary mentality. } \\
\text { Values cognitive ability } \\
\text { ("pass" or "fail") }\end{array}$ & Objective to the binary. & Part of formal curriculum. \\
\hline Informal & $\begin{array}{l}\text { Educator seen as authority } \\
\text { ("expert"); student is } \\
\text { "novice." } \\
\text { Educator-student interaction } \\
\text { is restricted. }\end{array}$ & $\begin{array}{l}\text { Educator becomes part of the } \\
\text { collective community with } \\
\text { students. }\end{array}$ & $\begin{array}{l}\text { Educator undertakes a } \\
\text { facilitator role. Blurring of } \\
\text { boundaries between educator } \\
\text { and student. }\end{array}$ \\
\hline Hidden & $\begin{array}{l}\text { Educator is unaware that } \\
\text { this is the status quo } \\
\text { (determines the "right" side } \\
\text { of the binary) as determined } \\
\text { by the dominant culture, } \\
\text { which causes and maintains } \\
\text { social injustices. }\end{array}$ & $\begin{array}{l}\text { Educator is aware of the status } \\
\text { quo (determines the "right" } \\
\text { side of the binary) as } \\
\text { determined by the dominant } \\
\text { culture, which causes and } \\
\text { maintains social injustices. }\end{array}$ & $\begin{array}{l}\text { Reciprocity is a key tenet for } \\
\text { social cohesion. Educator } \\
\text { establishes partnership with } \\
\text { community and service } \\
\text { providers. }\end{array}$ \\
\hline \multicolumn{4}{|c|}{ Learning level (students) } \\
\hline Informative & $\begin{array}{l}\text { Skills and knowledge } \\
\text { acquisition to develop the } \\
\text { expert. Objective learning. } \\
\text { Binary mentality. } \\
\text { Passive student. }\end{array}$ & $\begin{array}{l}\text { Skills and knowledge go } \\
\text { beyond theoretical } \\
\text { underpinnings. Examines their } \\
\text { relevance or applicability to } \\
\text { the real- world setting. } \\
\text { Identifies potential } \\
\text { contradictions. }\end{array}$ & $\begin{array}{l}\text { Skills and knowledge as it } \\
\text { relates to service rendered. } \\
\text { Competence in providing } \\
\text { service. }\end{array}$ \\
\hline Formative & $\begin{array}{l}\text { Socialization behaviors and } \\
\text { attitudes deemed as } \\
\text { "acceptable" to the status } \\
\text { quo, i.e., professional, } \\
\text { ethical, moral. }\end{array}$ & $\begin{array}{l}\text { Socialisation behaviors and } \\
\text { attitudes not acceptable. }\end{array}$ & $\begin{array}{l}\text { Identifies theory and practice } \\
\text { gaps/ contradictions. Reflects } \\
\text { on values relative to the } \\
\text { binary. }\end{array}$ \\
\hline
\end{tabular}




\begin{tabular}{|c|c|c|c|}
\hline & \multicolumn{2}{|c|}{ Pedagogy of Discomfort } & \multirow[b]{2}{*}{ Service-learning } \\
\hline & Spectator & Witness & \\
\hline Transformative & $\begin{array}{l}\text { Affective desensitization/ } \\
\text { denial of discomfort. }\end{array}$ & $\begin{array}{l}\text { Self-reflection. } \\
\text { Internal tensions arising at the } \\
\text { individual and societal level } \\
\text { are analysed. Contradiction } \\
\text { and ambiguity are } \\
\text { explicit/articulated. } \\
\text { Examines/challenges the } \\
\text { binary, status quo, and } \\
\text { dominant culture. Embraces } \\
\text { ambiguity. }\end{array}$ & $\begin{array}{l}\text { Self-reflection. } \\
\text { Subjective learning. } \\
\text { Dialogues with the binary. } \\
\text { Negotiates with the other to } \\
\text { reach a common (mutual) } \\
\text { understanding. Reciprocity is } \\
\text { the focus to enable change. } \\
\text { Uses discomfort as vehicle to } \\
\text { interpret experience. } \\
\text { Development of a change } \\
\text { agent. }\end{array}$ \\
\hline \multicolumn{4}{|l|}{ Learning stimuli } \\
\hline $\begin{array}{l}\text { Affective } \\
\text { Learning }\end{array}$ & $\begin{array}{l}\text { Not included in learning } \\
\text { process. }\end{array}$ & $\begin{array}{l}\text { Included in the learning } \\
\text { process to elucidate } \\
\text { ambiguities and } \\
\text { contradictions. }\end{array}$ & $\begin{array}{l}\text { Included in the learning } \\
\text { process to make meaning of } \\
\text { the experience. }\end{array}$ \\
\hline
\end{tabular}

The pedagogy of discomfort highlights uncomfortable experiences, which generally are manifested as affective learning through such emotions as frustration, anger, confusion, fear, and disappointment. These emotions commonly originate from encounters that do not "fit" into one's current frame of reference and, because they require a more complex perspective, transcend the binary. Both educators and students must step out of their comfort zones (isolation) and create a platform from which to collectively recognize what and how one has been taught to see or not to see (Aultman, 2005). By becoming aware of discomforting emotions and understanding how emotions are (re)produced enables educators and students to see how social (in)justices operate through our emotional connections to certain values and beliefs inculcated by formative learning. Through such mindfulness, emotional responses can be used as stimuli for learning.

\section{Bridging the Binary}

Mindfulness is about being fully present in all activities and thoughts in the moment, while remaining non-judgemental and in an empathic state of being (Grant, 2005). Grant (2005) held that incorporating mindfulness allows students to see that knowledge is negotiable, driven by a dynamic, engaging, and empowering process that can accommodate uncertainty. By facilitating learning in which affective experiences can be made explicit, one can articulate tacit knowledge from the hidden curriculum.

\section{Contextualizing Our Pedagogy of Discomfort}

Although this article is theoretical in nature, we acknowledge that the way in which we have engaged with the pedagogy of discomfort and the meaning we have extracted from it has been influenced by our context. Zembylas and McGlynn (2012) noted that every pedagogy of discomfort is "singular and unique and has to be examined within the social and historical context in which it is implemented" (2012: 45). 
Since 1994, South Africa's fledgling democracy has made considerable efforts at forming a rightsbased constitution which have been at the forefront of the government's reconstruction and development plan. However, 20 years on, South Africa is rated as the most unequal society in the world, with a Ginicoefficient of 0.7 (0 indicates total equality; 1 indicates total inequality) (Mayosi \& Benatar, 2014). The South African socio-political climate has been deeply scarred by a history of colonial oppression and apartheid on the one hand and the current democratic government's lack of transparency on the other. With a population comprising eleven official languages and expanding cosmopolitan cities, adjusting to diversity remains a challenge. Racial discrimination and xenophobic attacks, violence and injury, high unemployment and poverty, poor leadership and lack of accountability across the political and economic landscape - among other negative influences - stunt societal integration and transformation efforts. The quadruple disease burden, fragmentation of public and private health services, rural and urban health care inequalities, and low staff-to-patient ratios (leading to staff burnout) are pervasive across the health system (Mayosi \& Benatar, 2014), the context of our service-learning program.

Many contemporary South African thinkers maintain that the persistence of societal divisions is in large part due to the abrupt end of a healing dialogue started by the Truth and Reconciliation Commission, which was instituted by the first democratically elected government (Rampele, 2012). Today, this "dialogue" has been "replaced" by denial characterized by silence. South African society thus oscillates between instances of passive citizenry and public outrage (e.g., violent service-delivery protests) and the government's crisis management strategy of talking followed by inaction and lack of change. These power relationships and the current culture of government guard against raising discomforting dilemmas, ensuring that they remain muted in the background. The historic binary mentality of Black versus White remains a dominant rhetoric, negating a dialogue for healing. Therefore, space for engaging in praxis, critical self-reflection and action, and meaningful dialogue is cornerstone to effecting social transformation.

University students are increasingly representative of the "born free" generation, less interested in politics and more Western-orientated. Rampele (2012) illustrated this Westernization by contrasting "being" with "having." She noted that having (material wealth) has become a symbol of power and worth in post-apartheid South Africa. She equated "beingness" to Ubuntu, the summary of the meaning of the isiXhosa proverb from Southern Africa: "Umuntu ngumuntu ngabantu," which translates to "a human being is a human being only through its relationship to other human beings" (Marx, 2002) and is defined as "shared humanity" (Kwizera \& Iputo, 2011; Tutu, 2011). In our attempts to Africanize our servicelearning program, we have inculcated the ideals espoused by Ubuntu which relate primarily to the tenant of reciprocity (van Huyssteen \& Bheekie, 2013).

\section{Service-Learning in Pharmacy at the University of the Western Cape}

At the University of the Western Cape (UWC), South Africa, the Service-Learning in Pharmacy (SLiP) program has been embedded across the four-year undergraduate program. Two service-learning cycles are conducted per year. In preparation for the service experience, students are oriented to the service and community partnerships, learning objectives, assessments, and facility requirements. In keeping with the concept of relevance (Boelen, Dharmasi, \& Gibbs, 2012), our service-learning sites are situated in underserved communities rife with inequality. The learning sites include primary schools, informal settlements, primary health care clinics, community health care centers, and hospitals.

These unfamiliar settings test students' ability to navigate complex socio-cultural practices. Students are required to record their service experiences in a journal noting their observations, interactions, and experiences as primary evidence. After completing the service session, students engage in group reflection structured to uncover how their frame of reference resonates with present realities, exploring their coping strategies for dealing with underlying social processes and hidden phenomena through the use of thematic readers and videotaped footage. The main aim of this reflection is to critically analyse the theory and practice gaps in the pharmacy profession relative to students' experiences by first sharing 
those experiences within a small group before receiving feedback from the class. Students are prompted to interpret their social interactions, examine codes of conduct, discuss Afrocentric philosophies of humanity, and identify instances of reciprocity in the service-learning partnership. Group reflection is specifically aimed at evoking dialogue that encourages students to question their assumptions, traditions, cultures, rituals, and beliefs in the context of diversity and dynamic social forces. The group session serves as preparatory work toward compiling individual reflection reports.

An individual reflection report is divided into three stages of critical self-reflection using evidence from the service experience which is underpinned by the hidden curriculum (see Figure 3 ). The first stage requires students to describe a critical incident in which a particular service experience made them feel uncomfortable (i.e., context, or status quo). The discomfort may have arisen from interpersonal differences, attitudinal barriers, or through organizational practices or cultures that may have not resonated with their frames of reference. The second stage (the subject stage) requires students to describe their feelings of discomfort (self-disclosure) and examine their frame of reference that influenced their habitual patterns of thinking or acting in relation to the critical incident. During this stage, experiences are related through the binary mentality, leading to the emergence of contradictions. The third stage (the object stage) requires students to assume a witness stance in which they examine their frame of reference in depth, relative to a shared humanity perspective. The frame of reference was defined through social, cultural, historical, or traditional practices, and helped reframe their experience in dealing with diversity and tolerance by finding a way forward. At this stage students learn to deal with ambiguities, realize that there is no fixed truth, and adopt an action-oriented witnessing stance for consideration in the future. The purpose of designing the structured reflective process is to enable students to become conscious of ingrained emotions, values, and behaviors that limit transformation in a dynamic world rife with social inequality.

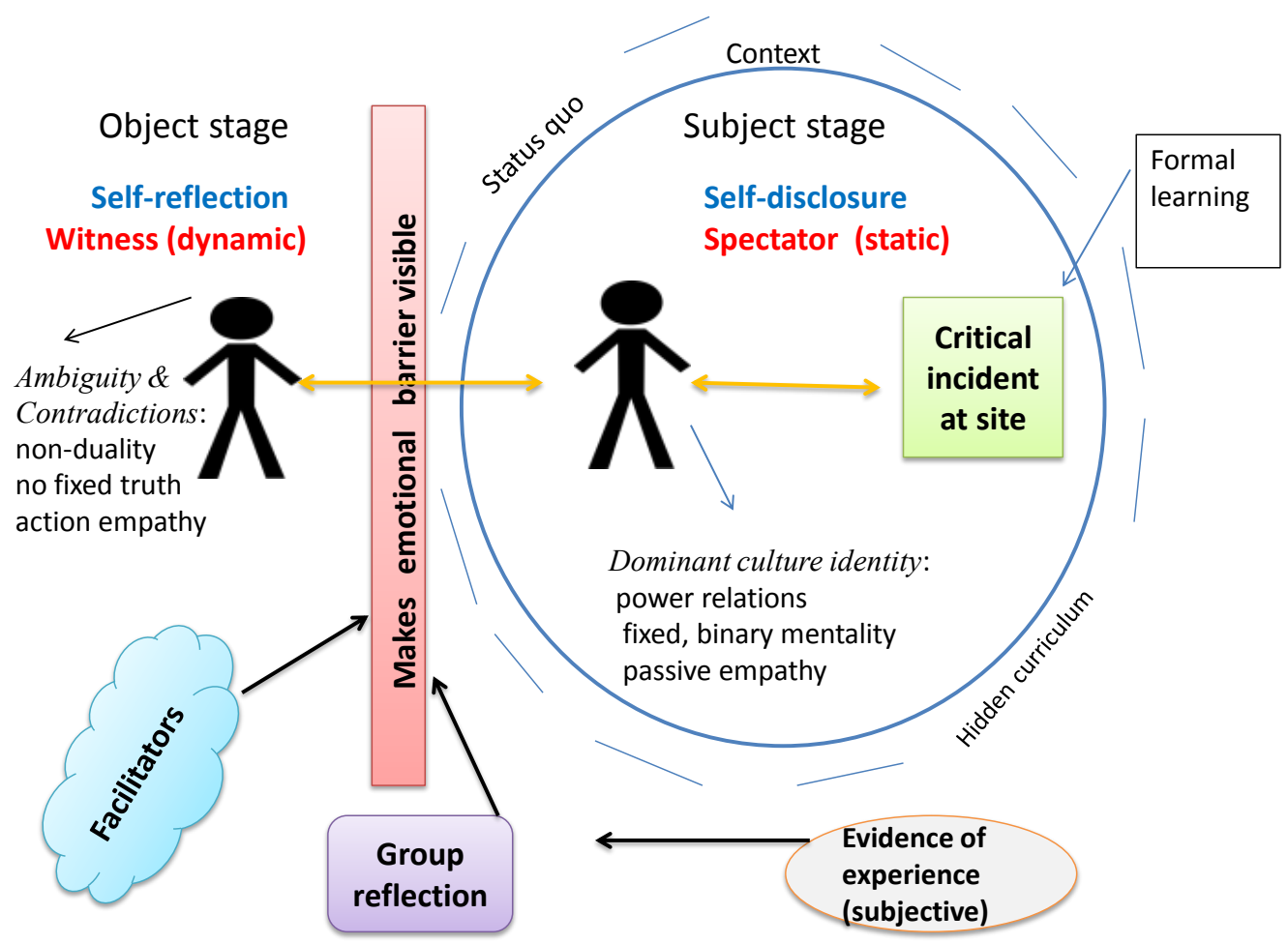

Figure 3. Representation of reflection process to move students from a passive spectator state to an action-oriented witness state. 


\section{Discussion}

The following discussion focuses on our experiences using the pedagogy of discomfort in the SLiP program. We discuss (1) the impact of the hidden curriculum on student learning, (2) how the pedagogy of discomfort has influenced the ways in which we, as educators, engage with students, and (3) the contradictions it raises in higher education as it relates to the hidden curriculum.

By starting a dialogue about emotions in the reflection sessions, students could articulate issues not traditionally shared in the classroom. By going out of their comfort zone into unfamiliar territory, students attempted to make sense of their site experiences. The reflective conversations revealed interpersonal barriers and issues of identity, power relations, and fear, students' habitual responses to socially constructed differences, and an inclination to retreat to the "us and them" mentality in relation to the community and/or service agency.

Students could relate explicitly their encounters with power relations imposed through the status quo of clinics and hospitals (between staff and students, students and patients, staff and patients). In most cases, their fear manifested itself as silence, especially when conflict emerged. Students justified the silence as a way of not imposing their views on others and rationalized their inability to engage across difference as a sign of respect for the other. Silence was attributed to their frame of reference, in which "respecting your elders" is viewed as a means to uphold values that are traditionally ingrained as part of students' formative development, thereby preserving the status quo. However, students also articulated that by keeping silent in conflict situations, power was conferred to the powerful other (confronter), reinforcing inequality.

As educators, we reflected on our own experiences as service-learning practitioners using the pedagogy of discomfort to unveil our binary mentality of educator versus student. We realized that in putting ourselves at a distance from the students, we were immersed in the role of the discipline expert whereby spectating was our modus operandi. Engagement with the hidden curriculum through students' affective experiences challenged the very foundation of our expert role by confronting us with questions for which our binary mentality did not have answers. The upshot of this contradiction was that we learned from the students. Becoming the "learner" enabled us to bear witness to ourselves, compelling us to become part of a collaboration through which we could articulate our own contradictions regarding higher education and inequality. For us, the pedagogy of discomfort exposes higher education institution's ivory tower binary mentality and apparent isolation from the status quo.

A paradigm shift away from the value attached to objective cognitive learning and the formal curriculum - which is viewed to be binary relative to the subjective affective learning and informal curriculum - is absent in higher education (Hafferty, 1998). Affective learning, in contrast to cognitive learning, has the potential to stimulate critical thinking not limited by the status quo. However, this paradigm shift is often limited as discipline-based science curricula generally operate as binaries, with limited linkage to the real-world context (Aultman, 2005). This then begs the question about the role of South Africa's higher education institutions in actively addressing issues of social injustice: How can affective learning and the hidden curriculum become part of mainstream teaching, research, and community engagement to collectively strengthen the dialogue about larger societal issues?

Higher education institutions need to devise ways to frame contradictions not as deficiencies but as opportunities for social transformation and engagement (Merriam, 2004). Mindfulness offers the ability to investigate the truth by embracing ambiguity and is often considered the hallmark of mature thinking. In this way, ambiguity can replace binary mentalities to transcend self-interest toward the creation of larger meaning (Henry \& Breyfogle, 2006). Wong (2004) demonstrated how the practice of mindfulness about feelings of discomfort unveiled habitual mental reactivity to difficult situations. She found that mindfulness is a practice which helps one to create a space where automatic mental activities are set aside to engage in dialogue about contradictions, reflecting a witnessing stage of self-development. 


\section{Conclusion}

Using the pedagogy of discomfort in the context of service-learning enabled us to appreciate the significance of the hidden curriculum (status quo) on student learning. By exploring students' emotions around discomfort, we could identify self-imposed and societal barriers which camouflage the development of students' critical thinking abilities. By exploring our own discomfort as educators, we realized how entrenched we and our institutions were in the binary mentality that limited our ability to dialogue about social injustice.

Higher education institutions should consider efforts to embrace ambiguity at the individual, institutional, and societal levels. The tenets, principles, and resources of service-learning programs potentially serve as conduits for creating space for ambiguity at all three levels.

\section{Acknowledgements}

The authors are grateful to the University of the Western Cape for administrative support in the ServiceLearning in Pharmacy (SLiP) program. We are indebted to the National Research Foundation, South Africa, for supporting our research. The SLiP partnership is pivotal in strengthening service-learning in the undergraduate curriculum.

\section{Author Note}

Angeni Bheekie, School of Pharmacy, University of the Western Cape, South Africa; Mea van Huyssteen, School of Pharmacy, University of the Western Cape, South Africa.

\section{Correspondence}

Correspondence regarding this article should be addressed to Angeni Bheekie, Associate Professor, School of Pharmacy, University of the Western Cape, Robert Sobukwe Road, Bellville 7530, South Africa. Phone:+2721-959-2977. E-mail: abheekie@uwc.ac.za

\section{References}

Aultman, J. M. (2005). Uncovering the hidden medical curriculum through a pedagogy of discomfort. Advances in Health Sciences Education, 10, 263-273. doi:10.1007/s10459-004-4455-2

Boelen, C., Dharmasi, S., \& Gibbs, T. (2012).The social accountability of medical schools. Education for Health, 25, 180-194.

Boler, M. (Ed.). (1999). Feeling power. Emotions and education. New York. Routledge.

Boyte, H. (2003). Putting politics back into civic engagement. The Campus Compact Reader, Summer, 58.

Bramming, P. (2007). An argument for strong learning in higher education. Quality in Higher Education, 13(1), 45-56. doi:10.1080/13538320701272722

Branch, W. T. (2005). Use of critical incident reports in medical education. Journal of General Internal Medicine, 20, 1063-1067.

Bringle, R. G., \& Hatcher, J. A. (1995). A service learning curriculum for faculty. Michigan Journal of Community Service Learning, 2(1), 112-122.

De Weerdt, S., Bouwen, R., Corthouts, F., \& Martens, H. (2006). Identity transformation as an intercontextual process. Industry and Higher Education, 20(5), 317-326.

Eyler, J., \& Giles D. E., Jr. (1999). Where's the learning in service learning? San Francisco: Josey-Bass. 
Flecky, K. (2011). Foundations of service learning. In K. Flecky \& L. Gitlow (Eds.), Service-learning in occupational therapy education: Philosophy and practice (pp. 1-12). London: Jones Bartlett.

Frenk, J., Chen, L., Bhutta, Z. A., Cohen, J., Crisp, N., Evans, T., \& Zuryak, H. (2010). Health professionals for a new century: Transforming education to strengthen health systems in an interdependent world. The Lancet, 376, 1923-1958.

Grant, E. (2005). The case for mindfulness in teaching and learning. South African Journal of Higher Education, 19(3), 555-565.

Hafferty, F. W. (1998). Beyond curriculum reform: Confronting medicine's hidden curriculum. Academic Medicine, 13(4), 403-407.

Henry, S. E., \& Breyfogle, M. L. (2006). Toward a new framework of "server" and "served": de (and re)constructing reciprocity in service-learning pedagogy. International Journal of Teaching and Learning in Higher Education, 18(1), 27-35.

Jarvis, P. (2009). Learning to be a person in society: Learning to be me. In K. Illeris (Ed.), Contemporary theories of learning: Learning theorists ... in their own words (pp. 21-34). New York: Routledge Taylor \& Francis Group.

Kegan R. (2009). What "from" transform? In K. Illeris (Ed.), Contemporary theories of learning: Learning theorists ... in their own words (pp. 35-52). New York: Routledge Taylor \& Francis Group.

Kwizera, E. N., \& Iputo, J. E. (2011). Addressing social responsibility in medical education: The African way. Medical Teacher, 33, 649-653.

Marx, C. (2002). Ubu and Ubuntu: On the dialectics of apartheid and nation building. Politikon: South African Journal of Political Studies, 29(1), 49-69.

Mayosi, B. M., \& Benatar, S. R. (2014). Health and health care in South Africa: 20 years after Mandela. The New England Journal of Medicine, 371(14), 1344-1353.

Merriam, S. B. (2004). The role of cognitive development in Mezirow's transformational learning theory. Adult Education Quarterly, 55(1), 60-68.

Mezirow, J. (1997). Transformative learning: Theory to practice. New Directions for Adult and Continuous Education, 74, 5-12.

Mezirow J. (1998). On critical reflection. Adult Education Quarterly, 48(3), 185-198.

Mezirow, J. (2003). Transformative learning as discourse. Journal of Transformative Education, 1(1), 5863.

Rampele, M. (2012). Conversations with my sons and daughters. Johannesburg, South Africa: Penguin Books.

Skilton-Sylvester, E., \& Erwin, E. K. (2000). Creating reciprocal learning relationships across sociallyconstructed borders. Michigan Journal of Community Service Learning, 7, 65-75.

Tutu, D. (2011). God is not a Christian. Chatham, UK: Rider Books.

Van Huyssteen, M., \& Bheekie, A. (2013). Ubuntu: Interconnecting the African spirit with servicelearning in pharmacy. In A. Smith Tolken \& J. du Plessis (Eds.), 5th International Symposium on Service-Learning 2013: Service-learning across the globe: From local to transnational. Stellenbosch, South Africa: SunMedia.

Wong, Y-L. R. (2004). Knowing through discomfort: A mindfulness-based critical social work pedagogy. Critical Social Work, 5(1).

Zembylas, M., \& McGlynn, C. (2012). Discomforting pedagogies: Emotional tensions, ethical dilemmas and transformative possibilities. British Educational Journal, 38(1), 41-59. 